\title{
The effect of using LED lighting in the growth of crops hydroponics
}

\author{
Luechai Promratrak* \\ 64 Udon Thani Rajabhat University, Thahan Rd., Muang, Udon Thani, 41000, Thailand
}

\begin{abstract}
This paper describes the use of artificial lights (Super Bright LEDs) for crop Hydroponics. To compare the growth of plants grown in natural light. The experiments are carried out in a closed dark enclosure, the control of the lights (LEDs) are $\mathrm{ON}$ for 16 hours a day. The Temperature was maintained at less than or equal to $30^{\circ} \mathrm{C}$ using an air pump cycling on and off, the run time on being 30 minute's. The design lamps used are super bright LEDs of different types, Fluorescent red to blue with a ratio of 3:1 when testing the growth of the 2 test plants (artificial light and led light) data was collected on the amount of light, temperature, and humidity, compared to growth. This data was then analyzed. The study found that the use of artificial light (LEDs.) the light intensity is lower than natural light having a temperature of $2-4^{\circ} \mathrm{C}$, with a $1,438-1,442$ Lux. The test plant using natural lighting and temperature grow the best in this study.
\end{abstract}

Keywords: LED lighting; growing from bulbs LED; crops; hydroponics

\section{Introduction}

Crop growing use the light from the LEDs. A variety of plants are used in everyday cooking, such as salads and vegetables. We humans have started to turn their attention to a healthier diet. Growing vegetables without chemicals. The wide use of chemicals over a number of years to control pests, and to accelerate growth of crops has started to have an effect on are health. In the market place we see products grown chemical free but comes with a relatively high price. Growing plants using artificial light and not in soil can be achieved easily, added advantage of using limited space unlike conventional crops. You do not the environmental, external factors also affecting the growth of crops. The response to these factors did not differ whether crops with conventional natural conditions or hydroponics that control the growth and development of plants. But there is an important factor.

Temperature-controlled growth of plants directly affects photosynthesis, respiration, mineral nutrition, dehydration.

Relative humidity directly affects the dehydration plant. When humidity is high, this making the crop less dehydrated. As a result, the supply of nutrients from the roots to the leaves fall and the temperature will rise. In addition, high humidity also causes certain diseases so a good level of humidity averages out at $80.54 \%$.

Lighting is another factor that affects the growth and development of plants. Because light is an important factor in building a food or photosynthesis of plants with chlorophyll this sensor uses energy to change carbon dioxide and water into carbohydrates and oxygen exposure other factors that affect the growth of plants, including wavelength, light intensity, duration of the light on the crop are features that affect the growth of plants grown with the hydraulic system. Hydroponics Inc. is a light intensity reference that if too much or too little light will result in reduced plant photosynthesis. Plants are growing in the tropics. Exposure to high intensity light and cropping in the open must be shaded to reduce light.

\footnotetext{
*Manuscript received January 20, 2017; revised April 10, 2017.

Corresponding author. Tel.: +66 81 9651588; E-mail address: luechai3086@ hotmail.com.

doi: $10.12720 /$ sgce.6.2.133-140
} 
The intensity of light is also related to the temperature. When the light is more intense temperature will rise accordingly. Growing crops in hydroponics you may overlook this relationship the temperature used to grow plants, plays a huge role on the activities of the foundation of the atmosphere, plants need carbon dioxide as a raw material for photosynthesis, in normal air with carbon dioxide to about 0.03 percent, which is sufficient for the needs of the plant, except in areas with dense vegetation, carbon dioxide may be limiting the growth of plants in the daytime due. Photosynthesis occurs more than carbon dioxide, and plants need oxygen to breathe, to transform the chemical energy stored in carbohydrates as energy use in various chemical reactions. In plants with hydroponics, the part above the ground is not a problem of lack of oxygen. Because the air oxygen is 20 percent, but the root of the solution is often a problem because of oxygen. Solubility in water is not sufficient to meet the needs of the plant must have oxygen in solution, which can be done using a pump or pumps or wind-powered renewable solution typically should maintain the level of oxygen in the solution is at $8 \mathrm{ppm}$.

Water quality is very important in growing plants with hydroponics. Because the plants get nutrients from the nutrient solution, which uses water as a key element if the water is contaminated with bacteria that causes. Diseases of the disease to spread quickly need to be sterilized before use, which could use chlorine or sodium hypochlorite, or calcium hypochlorite or chlorine if the water turbidity due to suspended solids is required. Filters out sediment out.

The vegetable salad Green Oak and hydroponics (Hydroponics) is derived from the Greek two words that Hydro (Hydro), which means "water" and that's Noble Inc. (Ponos) means. "Work" or "labour" the combination has meant that the work related to water. Because of growing plants in water containing dissolved nutrients to grow alternative crops, the soil we use to grow crops in general agriculture. The current crop with hydroponics technique invented crop of new variants by the medium used to grow not only confined water (Water culture), but the development of a medium or material. Planting (substrate) replacement soil and then watered with a nutrient solution, which we refer to as substrate for Culture (substrate culture) or aggregators Gate hydroponics (Aggregate hydroponics) techniques. All of these collectively as popular. Growing plants without soil (Soilless culture) [1].

So [2] overthrew the radiation study drug manufacturing plants without soil. The study found that growing plants without soil must consider several components. Such as a mineral nutrient solution. Monitoring closely this kind of plant material. The structure of a plant species of the selected plant. Including materials for the installation of a water circulation system. Automatic measurement solution in water measuring acidity-alkalinity of the water. Care slurry tank to control the outbreak. The solution should be both macronutrients micronutrients so that the plants grow up and have a good yield, and [3] Direk Aram study analysing the problem of growing plants without soil in Thailand. Found that most manufacturers use different rail lengths when used in Thailand. Making trouble solution temperatures, especially in summer. Lack of appropriate housing forms. Lack of proper food crops to market needs. Materials and equipment were planted at the right price. Knowledge in the field of personnel management that can be done. A patriotic, highly capable with carefully observant. Because of growing plants without soil to produce the crop. The vegetables are associated with living under conditions that require knowledge of both science and art together. In order to succeed, rather than building houses or equipment manufactured by machines. Therefore, the need to take action. Related to production management model to analyse production systems, such as the decision to produce alternative crops to raise funds and inputs to meet the needs of the market. Production planning, investment analysis to production. Management processes, including order processing and control integration. Various inputs to a limited extent, especially together. To get the output in a given period.

Vegetables grow in hydroponics. The current crop with hydroponics. There is a technique invented a new plant. Variants the medium used to grow is not limited to only using renewable ground water and then sprinkle with nutrient solution collectively. How to grow plants without soil (Soilless culture), vegetable salad, and green Oak look like shrubs. Or more stacked layers. Green leaves edges rounded streaky Fig. 1. Maturity is 40-45 days with 2-4 feet of flowers 10-25 flowers per inflorescence flower pollinating yellow petals. White or yellow flowers will bloom early especially during low temperature. 
Vegetable salad Green Oak the plants prefer cool climates. The optimum temperature for growth is between $10-24^{\circ} \mathrm{C}$ to grow in a climate of high. Growing the leaves are falling and plant substances like milk or a high-fibre, rubber, tough and bitter [4]. Xiao-Xue Fana, et al., (2013). study found their used red light-emitting diodes (LEDs, R) and blue light-emitting diodes (LEDs, B) to obtain the different light intensities of uniform spectra and investigated the effects of different light intensities on growth and leaf development of young tomato plants. The results showed that fresh weight, dry weight, stem diameter and health index were superior in plants grown under 300,450 and $550 \mu$ molm $-2 \mathrm{~s}-1$. The energy efficiency was highest under $300 \mu \mathrm{mol} \mathrm{m}-2 \mathrm{~s}-1$. When photosynthetic photon flux density (PPFD) increased from 50 to $550 \mu \mathrm{mol} \mathrm{m}-2 \mathrm{~s}-1$, a decrease in the specific leaf area (SLA) was observed. Under 300 and 450 $\mu \mathrm{mol} \mathrm{m}-2 \mathrm{~s}-1$, the thickness of leaves, palisade parenchyma and spongy parenchyma were the bigger, and the stomatal frequency and stomatal area per unit leaf area were also higher. The highest net photosynthesis rate (Pn) was observed under $300 \mu \mathrm{mol} \mathrm{m}-2 \mathrm{~s}-1$. Our results implied that, compared to other light treatments, $300 \mu \mathrm{mol} \mathrm{m}-2 \mathrm{~s}-1$ was more suitable for the culture of young tomato plants and there was no substantial gain from a PPFD above $300 \mu \mathrm{mol} \mathrm{m}-2 \mathrm{~s}^{-1}$ [5], and Huimin Li1, Canming Tang, Zhigang Xu. (2013). study the effects of different light qualities on rapeseed (Brassica napus L.) plantlet growth and morphogenesis in vitro College of Agronomy. Their study the light sources generally used for in vitro plant cultures are fluorescent lamps. To select a more efficient light source, the present study evaluated the effects of different light qualities on the growth and mor-phogenesis of rapeseed (Brassica napus L.) cultivar Westar plantlets in vitro. The plantlets were exposed to $60 \mu \mathrm{mol} \mathrm{m}-2 \mathrm{~s}^{-1}$ photosynthetic photon flux (PPF) for a $12 \mathrm{~h}$ photoperiod under the following six different light qualities: fluorescent lamps (FL), monochromic blue light-emitting diodes (LEDs) (B), monochromic red LED (R), and three mixtures of $\mathrm{B}$ plus $\mathrm{R}(3: 1,1: 1,1: 3)$ LED. The proliferation rate was greater in plantlets that were cultured under B light than those under FL. The differentiation rate, fresh mass, dry mass, concentration of chlorophyll a, soluble sugar concentration, stem diameter, leaf stomata abax-ial surface length, adaxial surface stomata frequency and transplantation survival rate were greater in plantlets that were cultured under $\mathrm{B}: \mathrm{R}=3: 1$ light than under FL. The concentration of starch and the spongy tissue length were higher in plantlets cultured under $\mathrm{R}$ light than those under FL. The $\mathrm{B}: \mathrm{R}=3: 1$ LED light was suitable for rapeseed plantlet growth in vitro and can be used as a priority light source in the rapeseed culture system according to its differentiation rate, proliferation rate, growth rate, and transplantation survival rate [6].

From such a condition, the researchers have devised a cropping using fluorescent LED. By cropping hydroponics. This is done to control the light bulb LED. Irrigation of vegetable crops and controls the temperature and humidity of the crop area in the closed enclosure In order to accelerate the growth of vegetable crops, using the light from the LED, Help control the growth of vegetation and produce a nontoxic product.

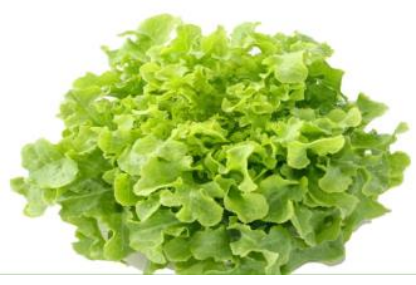

Fig. 1. Lettice green oak.

\section{Factors Affecting the Growth of Plants}

\subsection{Photosynthesis}

Humans cannot see the trees are green because plants do not have a green light absorbance. The green light on the human visible light and human vision to light. Which has wavelengths ranging from 380 to $700 \mathrm{~nm}$ by the sun to generate white light in a wavelength range of $470 \mathrm{~nm}$ to a light blue. And a wavelength of $670 \mathrm{~nm}$ at a red light. Colour is used in plant photosynthesis, most Fig. 2 [7]. 


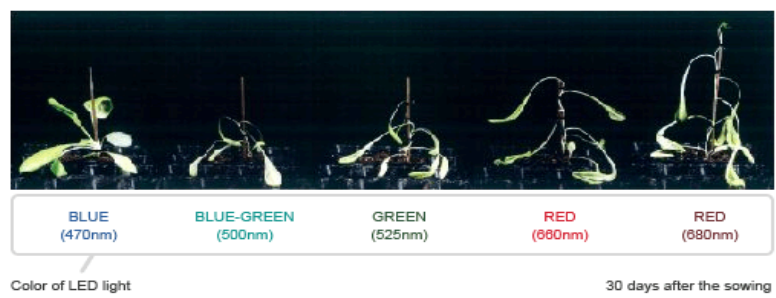

Fig. 2. Wave length of light affects plant.

\subsection{LED bulb light of the growing hydroponics}

LED lights are used to grow plants. Hydroponics is tubes ran the length of light waves that we want. In this case, we will choose the length of light waves at $430-460 \mathrm{~nm}$ and $630-660 \mathrm{~nm}$ estimated that due to the length of the light wave is ideal for the photosynthesis of plants and also help in the growth of more trees as well as in Fig. 3 [8].

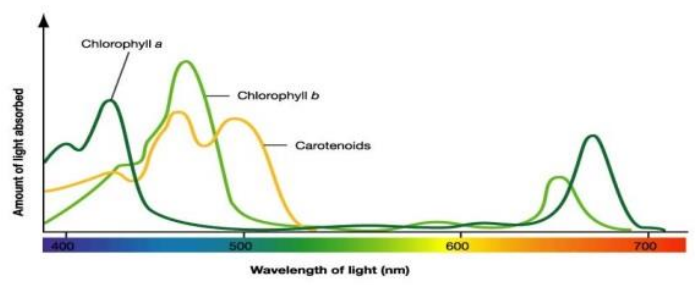

Fig. 3. Light bulbs LED.

The benefits of blue light (Wavelength 430-460nm) is the light waves Chlorophyll a, b can absorb more. Chlorophyll makes plants can stimulate the production of light even more. Accelerate the growth of the stem help stem strength and reducing stem elongation gives a strong and fresh green leaves of a red light (Wavelength 630-660nm) is the light waves Chlorophyll a, b can be better absorbed speeding up the flowers nourish the flowers and fruit to perfection. And help maximize productivity accelerate root growth gives strong roots accelerate the growth of the stem [9].

\section{Design and Test}

\subsection{Design cropping systems open to natural light}

Growing plants hydroponics provides natural light. The plant is grown using natural light in Foam boxes in a greenhouse for easy care and easy to move. Drill holes for 15 plants, each hole $7.5 \mathrm{~cm}$ apart the second box the size of carton used for a light cushion. The plant small box containing the siding sits on a plastic sheet over a water tank for the growing plants the roots of the plants sit in the water all the time. Growing using this box method provides the same solution in a ratio equal to planting of the light LED test sample. But does not use water circulation systems such as closed systems. Plants use nutrients added to the water, some fish farms use this growing method fish provide nutrients and the oxygen to the water when planting in foam boxes (Fig. 4).

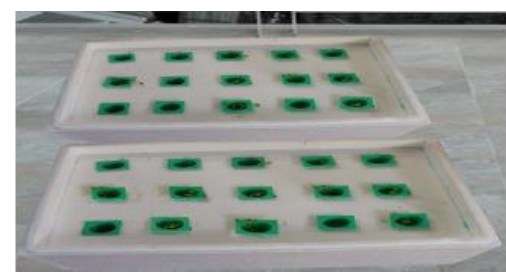

Fig. 4. Plants using natural sun light. 


\subsection{Cropping systems in greenhouses covered with synthetic fluorescent LED}

The planting of seedlings before planting in the enclosure and greenhouse has two stages as follows.

Stage 1 the first phase will be plant sampling vegetable seeds, which must be soaked in water use a sponge, into a drilled hole drop one seed. Soak them in the nursery for about two weeks the sponge cutting measures $2 \times 2 \times 2 \mathrm{~cm}$ bore hole for the seed. Fig.5a shows the germinating seedlings.

Stage 2 take the small seedling and select health plant to the growing frames size $60 \times 140$ fig. $5 \mathrm{~b} \mathrm{~cm} \mathrm{a}$ small hole for seedling to grow into a plant in the hydroponics enclosure and greenhouse at the same time. Each hole has a diameter of $3 \mathrm{~cm}$ each hole approximately $30 \mathrm{~cm}$ apart the enclosure has 36 spaces for the growing frames Fig. 4 show the boxes for the greenhouse test.

Fig. 6a showing the 36 holes for the growing frames the spacing of $30 \mathrm{~cm}$ so that the plant can receive light from the LED panels, a water sprinkler system supply's the water automatically.

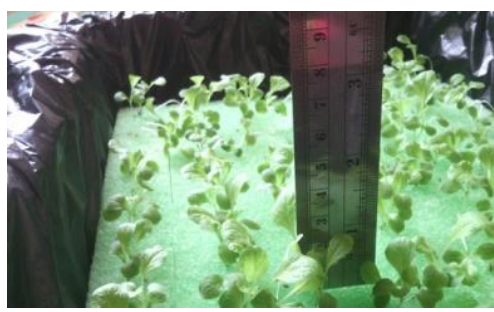

(a) Germinating seedlings Phase 1

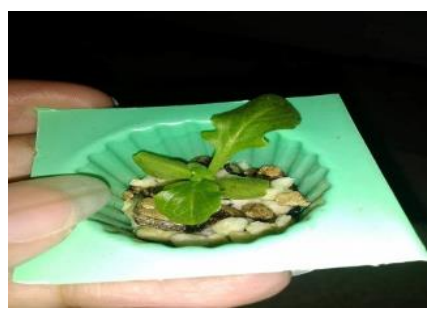

(b) Growing frames phase 2.

Fig. 5. Crop seeding starting to grow.

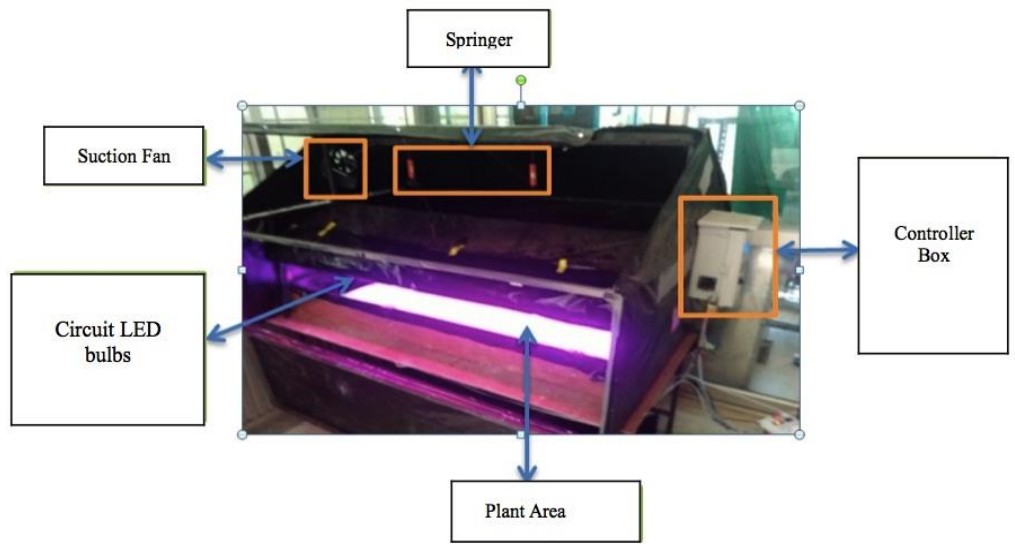

(a) LED panels.

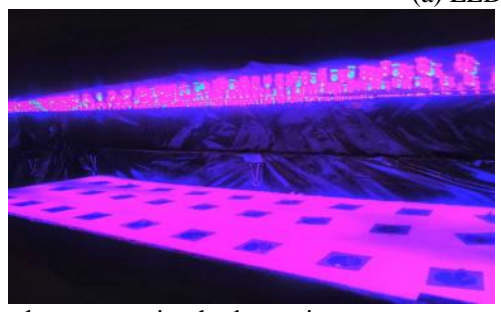

(b) Enclosure growing hydroponics system.

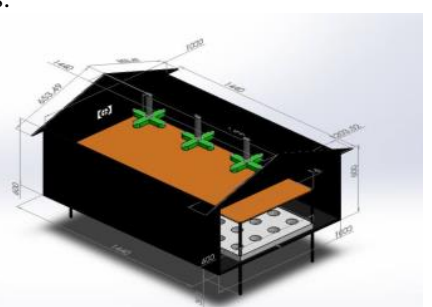

(c)The actual greenhouse growing.

Fig. 6. 6a LED arrangement in enclosure $6 \mathrm{~b}$ CAD drawing of enclosure $6 \mathrm{c}$ prototype enclosure.

\subsection{System control greenhouse growing hydroponics}

The system is controlled by the Arduino UNO R3 to control the on - off [10].

LED bulb to control the temperature control system. And the flow of slurry of plant-based system block diagram shown in Fig. 7. 


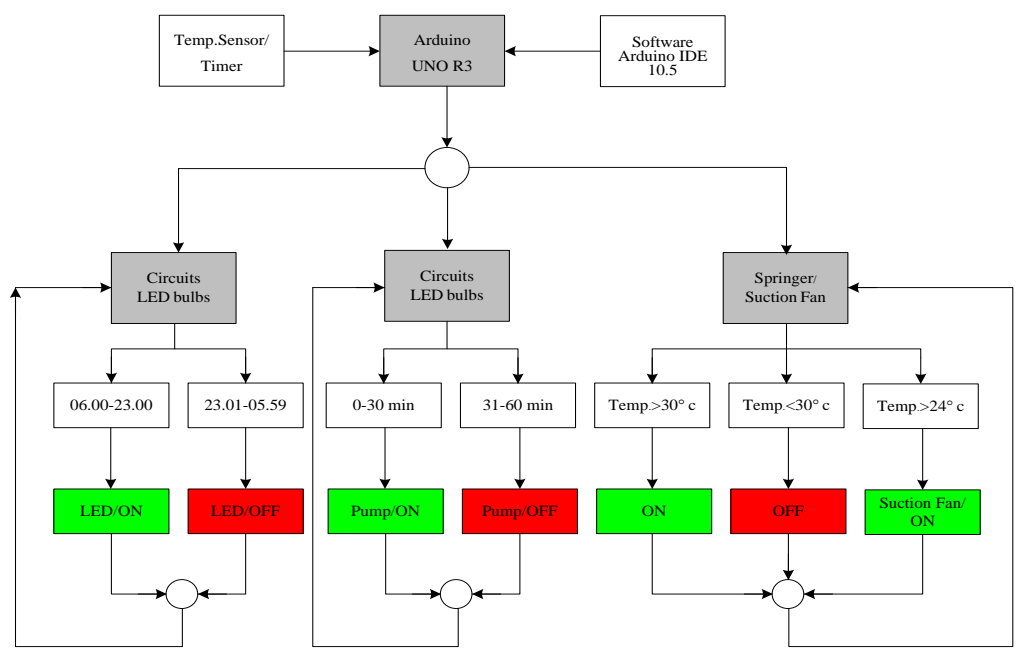

Fig. 7. Block diagram of system control.

Testing of the system by trial experiments on board with LED to show the status of the work, provided it works.

Test the functionality of a computer program to control greenhouse. The front LCD display is working on four different types of controlled temperature, humidity, time and date of the performance. (Fig. 8.)

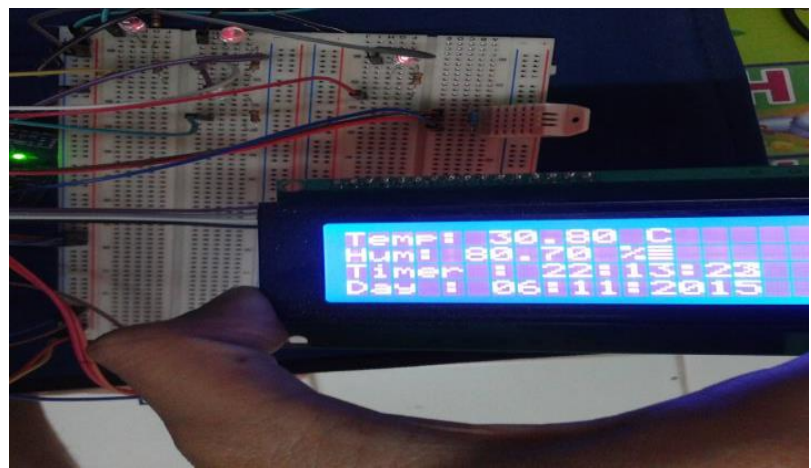

Fig. 8. Functional testing of drivers display LCD.

1. LED ON: 06.00-23.00 hrs. OFF: 23.01-05.59 hrs.

2. Pump ON: min less than 31 minutes OFF: min over 30 minutes.

3. Springer ON: Temp over $30^{\circ} \mathrm{C}$ OFF: Temp less than or equal to $30^{\circ} \mathrm{C}$.

4. Blower ON: Temp less than $24^{\circ} \mathrm{C}$.

\section{Results}

Data from laboratory studies of all data recorded 10 days of data were collected. The information is divided into two parts: the data from cultivation in closed enclosure light bulb LED. Information from the sun by planting in Table 1A, $1 \mathrm{~B}$.

Table 1A, 1B: shows that both of test samples are growing different RATES. The plants grown in greenhouses covered with the light from the LED is growing faster than the plants of natural light. By this growth, In addition to the factors of a different light now. There is also the factor of temperature and humidity are different too. The plants are growing different rate and can clearly see the growth by looking at Fig. 9 time aver growth rate the controlled environment make a more linear growth. 
Table 1. Results of the closed-loop plants in closed enclosure using LED light

\begin{tabular}{|c|ccccc|}
\hline & \multicolumn{5}{|c|}{ Plant by using LED light } \\
\hline Date & $\begin{array}{c}\text { Hight } \\
(\mathrm{cm})\end{array}$ & $\begin{array}{c}\text { Leaves } \\
\text { amount }\end{array}$ & $\begin{array}{c}\text { Average of } \\
\text { Light }(\text { Lux })\end{array}$ & $\begin{array}{c}\text { Temperatur } \\
\text { e }\left({ }^{\circ} \mathrm{C}\right)\end{array}$ & $\begin{array}{c}\text { Humidity } \\
(\text { RH } \%)\end{array}$ \\
\hline 1 & $\mathbf{3 . 8 3}$ & $\mathbf{3}$ & $\mathbf{1 4 3 8 . 5 9}$ & $\mathbf{3 3 . 0 7}$ & $\mathbf{4 7 . 6 7}$ \\
\hline 2 & $\mathbf{4 . 5 4}$ & $\mathbf{4}$ & $\mathbf{1 4 4 2 . 6 8}$ & $\mathbf{3 3 . 4 6}$ & $\mathbf{4 8 . 8 7}$ \\
\hline 3 & $\mathbf{5 . 1 0}$ & $\mathbf{5}$ & $\mathbf{1 4 4 1 . 1 3}$ & $\mathbf{3 4 . 4 3}$ & $\mathbf{5 9 . 9 5}$ \\
\hline 4 & $\mathbf{5 . 4 8}$ & $\mathbf{6}$ & $\mathbf{1 4 3 8 . 7 2}$ & $\mathbf{3 7 . 2 7}$ & $\mathbf{6 4 . 4 0}$ \\
\hline 5 & $\mathbf{5 . 9 7}$ & $\mathbf{6}$ & $\mathbf{1 4 4 0 . 3 1}$ & $\mathbf{3 6 . 5 3}$ & $\mathbf{6 5 . 3 5}$ \\
\hline 6 & $\mathbf{6 . 4 2}$ & $\mathbf{7}$ & $\mathbf{1 4 3 9 . 8 6}$ & $\mathbf{2 6 . 6 7}$ & $\mathbf{3 3 . 4 5}$ \\
\hline 7 & $\mathbf{6 . 8 7}$ & $\mathbf{7}$ & $\mathbf{1 4 3 9 . 9 5}$ & $\mathbf{2 5 . 4 0}$ & $\mathbf{3 2 . 8 7}$ \\
\hline 8 & $\mathbf{7 . 2 9}$ & $\mathbf{8}$ & $\mathbf{1 4 3 8 . 8 1}$ & $\mathbf{3 1 . 8 5}$ & $\mathbf{5 7 . 5 0}$ \\
\hline 9 & $\mathbf{7 . 7 5}$ & $\mathbf{8}$ & $\mathbf{1 4 3 8 . 8 6}$ & $\mathbf{3 5 . 6 0}$ & $\mathbf{5 8 . 8 7}$ \\
\hline 10 & $\mathbf{7 . 7 5}$ & $\mathbf{8}$ & $\mathbf{1 4 3 8 . 6 3}$ & $\mathbf{3 7 . 3 5}$ & $\mathbf{7 2 . 2 3}$ \\
\hline
\end{tabular}

Table 2. Results of the closed-loop plants in greenhouses using SUN light

TABLE 1B

\begin{tabular}{|c|c|c|c|c|c|}
\hline \multirow[b]{2}{*}{ Date } & \multicolumn{5}{|c|}{ Plant by using the Sun light } \\
\hline & $\begin{array}{l}\text { Hight } \\
(\mathrm{cm})\end{array}$ & $\begin{array}{l}\text { Leaves } \\
\text { amount }\end{array}$ & $\begin{array}{l}\text { Average of } \\
\text { Light (Lux) }\end{array}$ & $\begin{array}{l}\text { Temperatur } \\
\text { e }\left({ }^{\circ} \mathrm{C}\right)\end{array}$ & $\begin{array}{l}\text { Humidity } \\
\text { (RH \%) }\end{array}$ \\
\hline 1 & 3.74 & 3 & 1738.13 & 36.69 & 35.91 \\
\hline 2 & 4.08 & 4 & 1536.72 & 34.65 & 43.58 \\
\hline 3 & 4.31 & 5 & 1552.32 & 36.65 & 49.64 \\
\hline 4 & 4.45 & 5 & 1864.27 & 38.74 & 57.21 \\
\hline 5 & 5.02 & 5 & 1745.36 & 37.91 & 53.42 \\
\hline 6 & 5.47 & 6 & 1455.45 & 27.67 & 39.11 \\
\hline 7 & 5.98 & 6 & 1444.77 & 25.54 & 36.07 \\
\hline 8 & 6.42 & 7 & 1464.77 & 33.92 & 45.75 \\
\hline 9 & 6.67 & 7 & 1634.27 & 36.56 & 53.43 \\
\hline 10 & 6.67 & 7 & 1724.27 & 36.58 & 56.13 \\
\hline
\end{tabular}

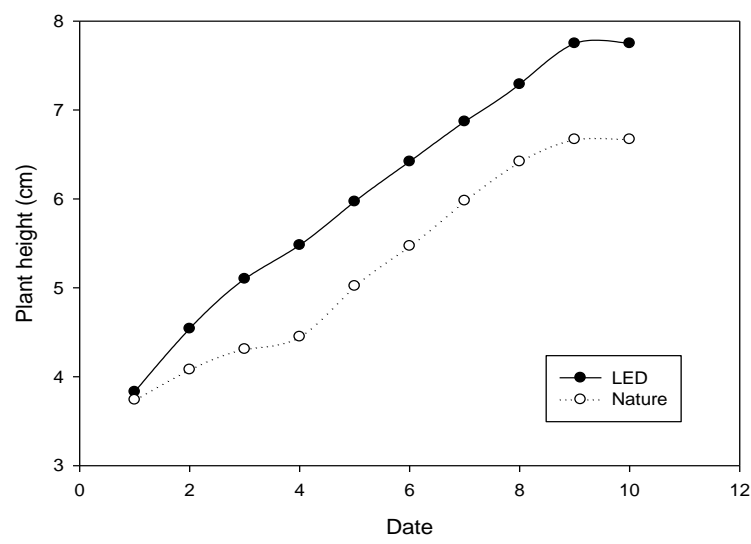

Fig. 9. Compare the growth of lettuce oak.

The plants growing in a closed enclosure using light LED bulbs (LED) are grown using greenhouse natural light. 


\section{Conclusion}

Plants need the wavelength range 400-520 nm wavelength range of 610-720 nm blue light and a red light wavelengths. The study tested the use of LED for lighting in the plant instead of natural light. The results were that the light from the LED can help plants grow. In this study, using a mix of light bulbs, LED red and blue in the ratio of 3:1, which colour is reddish purple. When experimenting with light vegetable salad in a closed environment for a period of 10 days, 16 hours a day, the results is the plants from the LED light are growing steadily. In the test the light from the LED and the temperature can be controlled at a constant level. Salad vegetables grow better if the lighting and temperature are natural sun light.

\section{Acknowledgment}

The author would like to thank a President and the Research and Development Institute Udon Thani Rajabhat University for funding this project.

\section{References}

[1] Overthrew the Radiation Therapy. (2001). The production of horticultural crops without soil. Edition 1: Publisher Odeon Store.

[2] Benjawan lertvijitcharat. (2013). Emulenergy. LED. [Online]. Available: http://library.cmu.ac.th/energy/content.php type $=$ knowleds_full\&id=3. 2 October 2015.

[3] CCS. Inc. (2014). Relationship with Wavelengths. Colour of LED Light. [Online]. Available: http://www.ccsgrp.com/s_02.html.

[4] Direk T. Crops without soil. Edition 3. Bangkok: SE-ED Ltd; 2006.

[5] Xiao XF, et al. Effects of light intensity on the growth and leaf development of young tomato plants grown under acombination of red and blue light, a College of Agronomy, Nanjin Agricultural University, Nanjing 210095, People's Republic of China b Xuzhou Institute of Technology, Xuzhou 221008, People's Republic of China c Kinsun, Optoelectronic Co., Ltd. Donguan, Guandong 513563, People's Republic of China, 2013.

[6] Huimin L, Canming T, Zhigang X. The effects of different light qualities on rapeseed (Brassicanapus L.) plantlet growth and morphogenesis in vitro College of Agronomy, National Key Laboratory of Crop Genetics \& Germplasm Enhancement, Nanjing Agricultural University, Nanjing 210095, Jiangsu, People’s Republic of China. University, Thailand, 2013.

[7] Somporn K. (2013). Hydroponic vegetable growing system devices in the workplace. The water circulation system. Vegetable growing hydroponic system. [Online]. Available: http://kmlo.crma.ac.th/km/wp-content/uploads/2014/05/56-903.pdf.

[8] Luechai P. Research and Development in Electronics. First edition, Department of Electronics Technology and Electrical Engineering, Faculty of Technology, Udon Thani Rajabhat, 2015.

[9] Thanakorn N. (2012). Control temperature and relative humidity in greenhouses, hydroponics. System Control temperature and humidity. [Online]. Available: http://www.tci-thaijo.org/index.php/EAUHJSci/article/ Download/25523/21681

[10] Ekachai M. (2013). Micro controller Arduino. Control Arduino. [Online]. Available: http:// www.engineer007.com/index.php 